\title{
The Research Competence Development of Students Trained In Mathematical Direction
}

\author{
Ilnar F. Yarullin \\ Kazan (Volga region) Federal University, RUSSIA \\ Natalia Aleksandrovna Bushmeleva \\ Vyatka State Humanities University, RUSSIA \\ Ivan I. Tsyrkun \\ Belorussian State Pedagogical University, BELORUSSIA
}

•Received 17 June $2015 \bullet$ Revised 22 August $2015 \bullet$ Accepted 19 September 2015

The relevance of the issue described in the article is substantiated by the need of modern Russian society for professional people who are able to work in different situations and solve vital and professional problems successfully. There are, however, opportunities based on pedagogical theory and practice to solve this problem, in particular, by means of students' research competence development at Russian universities. The objective of the article is to develop a model of the research competence development of students trained in the mathematical direction in the process of studying specific mathematical disciplines. This is based in the context of information and communication environment in the light of competence-based, personal-activity and system approaches on the basis of mathematical, information and pedagogical knowledge integration.

Keywords: education competence model, research skills and habits, research competence, students' educational-research activity, students' scientific-research activity

\section{INTRODUCTION}

The present day specifies more requirements for a person's ability for selfimprovement and self-development, and professional and social mobility, to the level of intellectual development as these qualities determine human value as a personality and as an expert in modern society (Biktagirova \& Valeeva, 2013). Therefore the system of higher education has to provide for the development of these qualities to ensure the university graduates' life-long self-improvement. This goal may be realized through the competency-based approach which the Federal law "About education in the Russian Federation" has defined as the major practical method of higher education modernization in regard to the increase of its quality and labor market

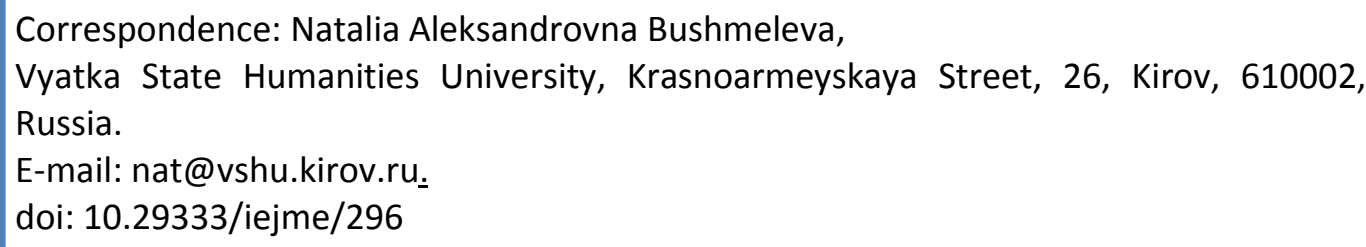

requirements (Latypov\&Sabirova, 2013; Zhirnova \& Absalyamova, 2013). Many 
scientific works (e.g. Pidkasisty, Belyaev, \& Khutorskoi, 2013) are devoted to the issues of theoretical substantiation of education modernization and students' training system improvement for professional activity in the context of present-day conditions.

One of the major vocational training objectives is the basis and experience development of students' professional activity at the research level. Readiness to conduct scientific research make up part of this development, as are the skills of research behavior, mastering practical methods and technologies in the specific area determined by the training direction, and the ability to work in professional situations of uncertainty (Abdrafikova, Akhmadullina, \& Singatullova, 2014; Skornyakova, 2013; Zabelina, 2015).

Students' knowledge as a future expert has to possess a completeness of the system they will work within. The graduate student has to be able to interpret unfamiliar phenomena in the theory and practice in order to solve vital and professional issues, to master methods of theoretical and applied researches, and to be able to draw the correct conclusions from the conducted researches. The listed requirements are relevant for students' professional development in any direction, including mathematics.

The analysis of traditionally developed forms, methods and means of organization and conducting studies in a higher education institution shows that training in a higher education institution does not fully correspond to the tendencies of modern mathematical education; there prevails a reproductive character of training materials. As a result, many university graduates are not capable of working effectively to develop innovative technologies since the success of learning mainly depends on students' thinking activity.

Such students do not feel the need to comprehend theoretical mathematical facts, they are unable to conduct the search for new scientific mathematical information, and they do not possess the critical skills to prove statements, and, as a result, their perspicacity in the profession is low. They are not innovation- or creative-oriented. One of the ways to solve this is to understand that research competence development is a core training requirement for students to be trained in the mathematical direction.

The analysis of scientific research and educational practice shows that the process of students' research competence development has not been studied at the theoretical and technological levels, hence it is not being actively introduced into training practice.

\section{METHODOLOGICAL FRAMEWORK}

\section{Stages to solve the issue of effective research competence development}

Nowadays, scientists express various opinions in regard to competency-based approaches in education. At the same time, the analysis of sources allows us to draw a conclusion that there is no uniform, standard definition of the concept "competence", besides, there is a different interpretation of the terms "competence" and "competency". To differentiate the semantic meaning of these concepts we will consider Khutorskoi's point of view, who understands competence as "some aloof, beforehand set requirement to a learner's educational training, and competency as already accomplished personal quality (set of qualities) and the minimum experience in relation to the activity in the designated sphere" (Khutorskoi, 2013).

In many works (e.g. Khutorskoi, 2011; Komarova, 2008; Shadrikov, 2006; Skornyakova, 2013), various approaches to the concept of research competence are singled out: It is considered as a personality's integrative quality; as a personality's special property; and as an ability for research activity. Its fundamental elements are 
the body of knowledge, skills and habits that the student has in a certain subject sphere, and the ability for independent cognitive activity.

Some authors (Khutorskoi, 2009; Lebedev, 2009) propose the classification of educational competences according to three levels that correspond to the content of education; subject, all-subject, and meta subject; which all relate to the general education content.

The research competence is an example of meta-subject competence. It includes the whole complex of educational competences directly connected with thought, search, logic, and creative processes of students' knowledge mastering.

Some authors (e.g. Edwards \& Osipova, 2011) pay attention to the converting nature of research competence and represents it as an integrated personal quality. This is expressed as the readiness and ability to master and receive systems of new knowledge independently, as a result of the transfer of an activity semantic context, from functional to converting, on the basis of already available knowledge, abilities, skills and ways of activity.

In our opinion, spontaneous teaching of some skills of research activity during traditional training sessions and extra curricula work cannot serve the basis for competence formation of the designated competence.

Only systematic use of opportunities of several modern pedagogical technologies (research, design, information and communication, etc.) may provide the solution to the objective.

Many scientists speak about the availability of a huge potential in the research competence development on the material of different areas in mathematics.

To solve the issue of research competence development of students trained in the mathematical direction it is necessary to do the following:

1. Change the system analysis of the research competence structure to select methodological and methodical justification of its development process;

2. Define the body of student's research competences and their characteristics within professional and mathematical training in higher education institutions;

3. Construct the model of research competence development where goals, tasks, structure, logic, content, methods, forms, and means of implementation are the body of this process;

4. Select traditional and innovative technological strategies to involve students in research activity;

5. Develop techniques aimed to develop research competence based on the modeling of educational researches and arrangement of independent research activity;

6. Develop a compendium of research projects that unite content and technological aspects of the research activity on the material of specific mathematical disciplines;

7. Formulate criteria to assess the level of students' research competence;

8. Develop the technology to realize the model and to verify experimentally its efficiency in regard to students' motivational increase in educational and research activity, and their involvement into the research process.

\section{Content, structure and body of research competences}

\section{The content}

The content of the research competence represents the body of four interconnected components: cognitive, motivation-goal, activity-evaluation, and communicative.

The cognitive component represents a set of students' theoretical and methodological knowledge, the knowledge of the essence and technology of the main 
research methods, ability to see problems, observation, and independence of judgments, high intelligence, good memory, aspiration to express own truth.

The motivation-goal component represents the understanding of this knowledge for oneself as a personality and for professional activity, and awareness of the research position importance in the professional activity. Thus, it is the system of emotional-volitional attitudes towards oneself (the availability of a high selfestimation), to the surrounding world, to people, and to the professional activity and opportunities of self-improvement.

The activity-evaluation component represents the ability to use this knowledge for the solution of practical tasks, the ability to carry out research actions to solve professional research tasks (ability to generate a large number of new ideas, originality of thinking, ability to react to the situation in the original way, ability to improve the object).

The communicative component represents the readiness to help, ability to work in a team, ability to coordinate actions, and to collaborate.

\section{The body of student's research competences}

Value-semantic competences formed in the course of research activity include the student's ability to see and understand the surrounding world, to orient in it, the ability to choose specific and semantic settings for actions and acts, to make decisions.

Common cultural competences are defined by a circle of questions in which the student has to be well-informed, and an experience of activity which the student has to possess. It is possible to note the experience to perceive the scientific picture of the world.

As for educational-cognitive competences, it is the body of student's competences in the sphere of independent cognitive activity, including elements of logical, methodological, all-educational activity correlated to real cognizable objects. Here the level of knowledge and abilities to organize a goal-setting, planning, analysis, reflection, self-assessment of the research activity is defined.

Information competences include the ability to search, analyze and select necessary information, to organize, transform, keep and transfer it independently.

Communicative competences assume the knowledge of necessary languages, ways of interaction with surrounding people, skills to work in teams performing various social roles.

Social-labor competences mean the mastering of knowledge and experience of activity in social-labor and civil-public spheres.

Competences of personal self-improvement are directed to the development of ways of activity in own interests and opportunities; it implies continuous self-knowledge, and the development of personal qualities necessary for the modern person.

See Figure 1 as a structure of research competence. It shows that it is impossible to create all the components of competency and competences by means of only one pedagogical technology.

Technological strategies, that allow the involvement of students in research activity, are research, design, information-communication, and didactic multidimensional technologies in the educational process.

\section{Mathematical tasks aimed at developing research competency}

The solution of mathematical tasks arising from real life, economic, and other situations plays an important role to develop the research competence that promotes students' research activity. It provokes students to more meaningful study of theoretical mathematical facts and methods of tasks solution in a higher education institution, and to their application in practice, allowing for the creation of a certain experience. 


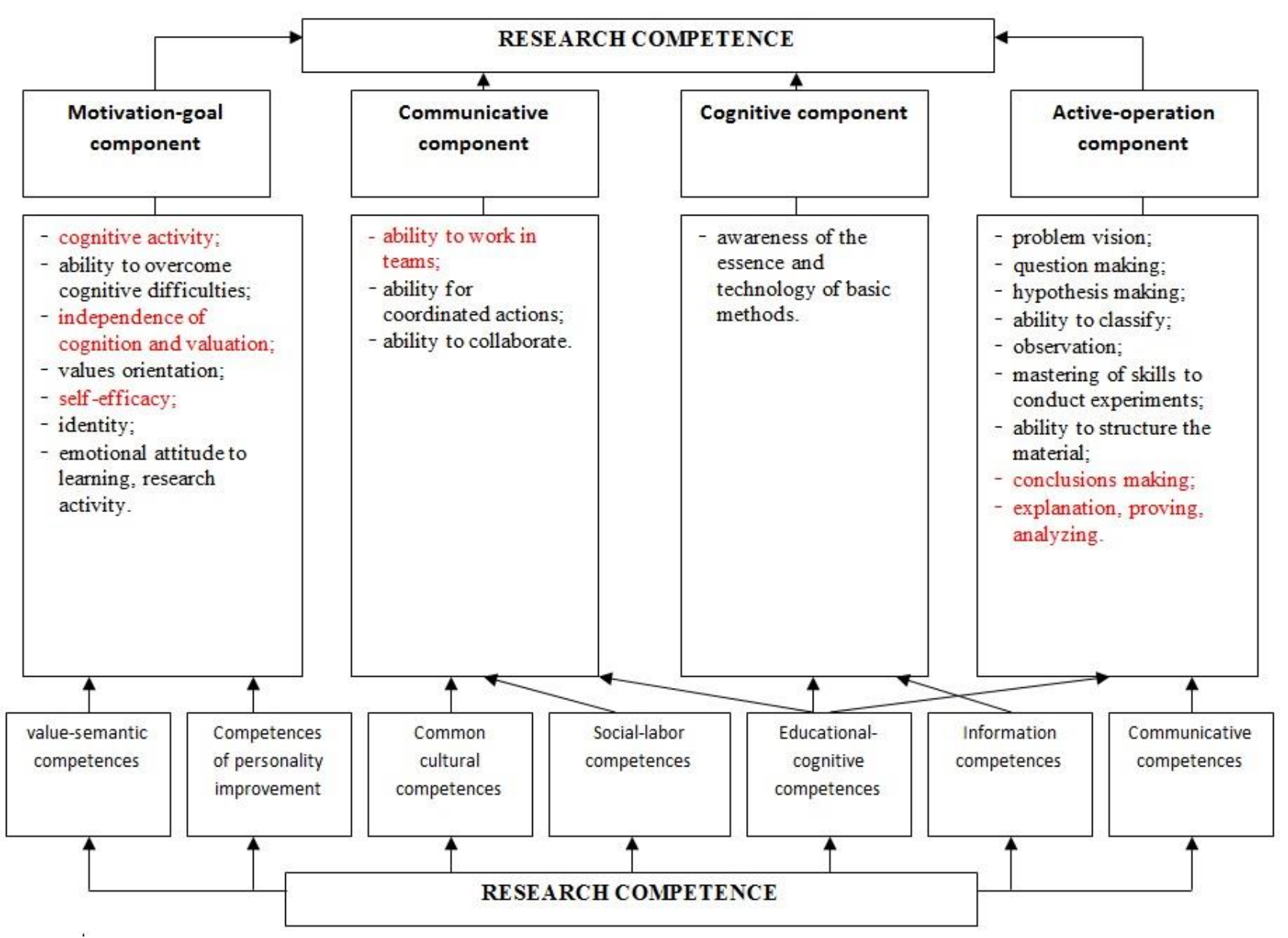

Figure 1. Structure of research competence

In Vyatka State Humanities University (Kirov, Russia), a sufficient level of experience has been achieved in regard to research competence development by means of mathematics in the process of education-research and scientific-research works implementation. The lessons of mathematics are aimed to develop all of the above components of students' research competence (the ability to formulate a task, to analyze the available information, and to select solution methods) (Bushmeleva \& Razova, 2014).

The development of the cognitive component of students' research competence (mathematical direction) assumes the development of the ability to work with original sources, various reference books, to systematize material, and to choose methods and ways of practical activities. It occurs in the course of studying all sections of disciplines of a mathematical cycle: "Algebra", "Geometry", "Mathematical analysis", "Probability theory and mathematical statistics", "Optimization methods", "Methods of nonlinear optimization problems solution", "Research of operations", and "Game theory", etc. when students become acquainted with the basic concepts, definitions, theoretical facts, and learn to choose, from the available conditions, adequate methods of solution from the diversity available.

The motivation-goal component of the research competence assumes personal interest and motivation of the student to study this mathematical discipline. The development of student's motivation-goal component of the research competence is especially manifested during the study of probability theory and mathematical statistics. Let us regard as an example the subject "Laws of Distribution"; the study of it begins with the consideration of the essence and importance of the laws of random 
variables distribution and conditions of their emergence. Using real practical examples, perhaps of economic character (data of bank interest rates, values of product cost, enterprise revenues), students calculate numerical characteristics of the selection, build histograms and grounds of frequencies, and verify the hypothesis of the normal law of random variables distribution.

The motivation of success achievement also plays an important role in the success of the research competence development. Students with a high level of motivation search information more actively, they are more resolute, initiative and more often show creative and research abilities.

The effective-operational component is formed when students perform practical operations, for example, when they learn to carry out the selection of objects from the general totality in regard to the quantity sign determined by them, etc. Table 1 shows a comparison between traditional and research tasks.

Let us give examples of research projects that unite content and technological aspects of research activity on the material of mathematical disciplines proposed to students at training sessions.

1. To investigate multi component connections between the quality of general secondary education and success of training in a higher education institution for students trained in "Physics", "Mathematics and computer sciences", or "Applied mathematics and informatics". The quantitative signs to be considered are: 1) GPAs of the school certificate; 2) GPAs of the humanitarian; 3) GPAs of exact disciplines; 4) GPAs of the majors at entering the university (the Russian language, mathematics and physics).

2. To investigate the dependence of a person's response rate, thinking rate on physical parameters (height, length of fingers).

3. To describe in detail ten ways of quadratic equations solution, including ways not studied in school and higher school courses of mathematics.

4. Using printing sources or electronic resources, to find the description of a conflict situation with the participation of two interested parties, and to present the situation in the form of a matrix game. To formalize the solution of the conflict situation: 1) to describe all possible strategies of both players; 2) to make the table (if players' interests are opposite) or two (if players' interests do not coincide), in which prizes of players in each of the situations are verbally described; 3 ) to pass reasonably to the quantitative description of players' prizes, to write down the obtained result; 4) to formulate the criterion of players' optimal strategies and to write down it mathematically; 5) to prove possible methods of finding optimal strategies; 6) to find definite strategies of the person who makes the decision, to give them economic interpretation; 7) to analyze the obtained solution.

Table 1.The structure of traditional and research tasks

\begin{tabular}{ll}
\hline Traditional task & Research task \\
\hline The statement of the problem includes all necessary & $\begin{array}{l}\text { The statement of the problem causes the necessity to obtain } \\
\text { such a solution when there arises a cognitive need in new } \\
\text { information on the basic data and a supposed result. }\end{array}$ \\
$\begin{array}{l}\text { The standard solution is available. } \\
\text { The student has knowledge to classify the task (refer it to a }\end{array}$ & $\begin{array}{l}\text { The stand solution is not available or it not known for a } \\
\text { student. }\end{array}$ \\
$\begin{array}{l}\text { specific type of tasks) and realize the algorithm of its } \\
\text { solution. }\end{array}$ & $\begin{array}{l}\text { The student has opportunities (resources) to perform the } \\
\text { the student solves the problem in a formal way. }\end{array}$ \\
$\begin{array}{l}\text { Mechanical memorizing. } \\
\text { The student's personality is manifested; student's actions } \\
\text { depend on their motives and abilities. }\end{array}$ \\
Obtaining personal experience.
\end{tabular}

\section{Assessment criteria of the research competence development level}


On the basis of the experience of educational-research and scientific-research activity arrangement, it is possible to draw a conclusion that students' research competence and mathematical competences are both interconnected and interdependent.

It allows to formulate the criteria of students' research competence development in Table 2. All components of the research competence act as the criteria of its development and express the most general intrinsic sign according to which the evaluation takes place. The criteria include the body of the main singled out indicators.

It should be noted that these criteria and indicators are in close unity and interaction, thus forming a complete system and help to orient in research activity, to achieve goals.

Table 2.Criteria of research competence development

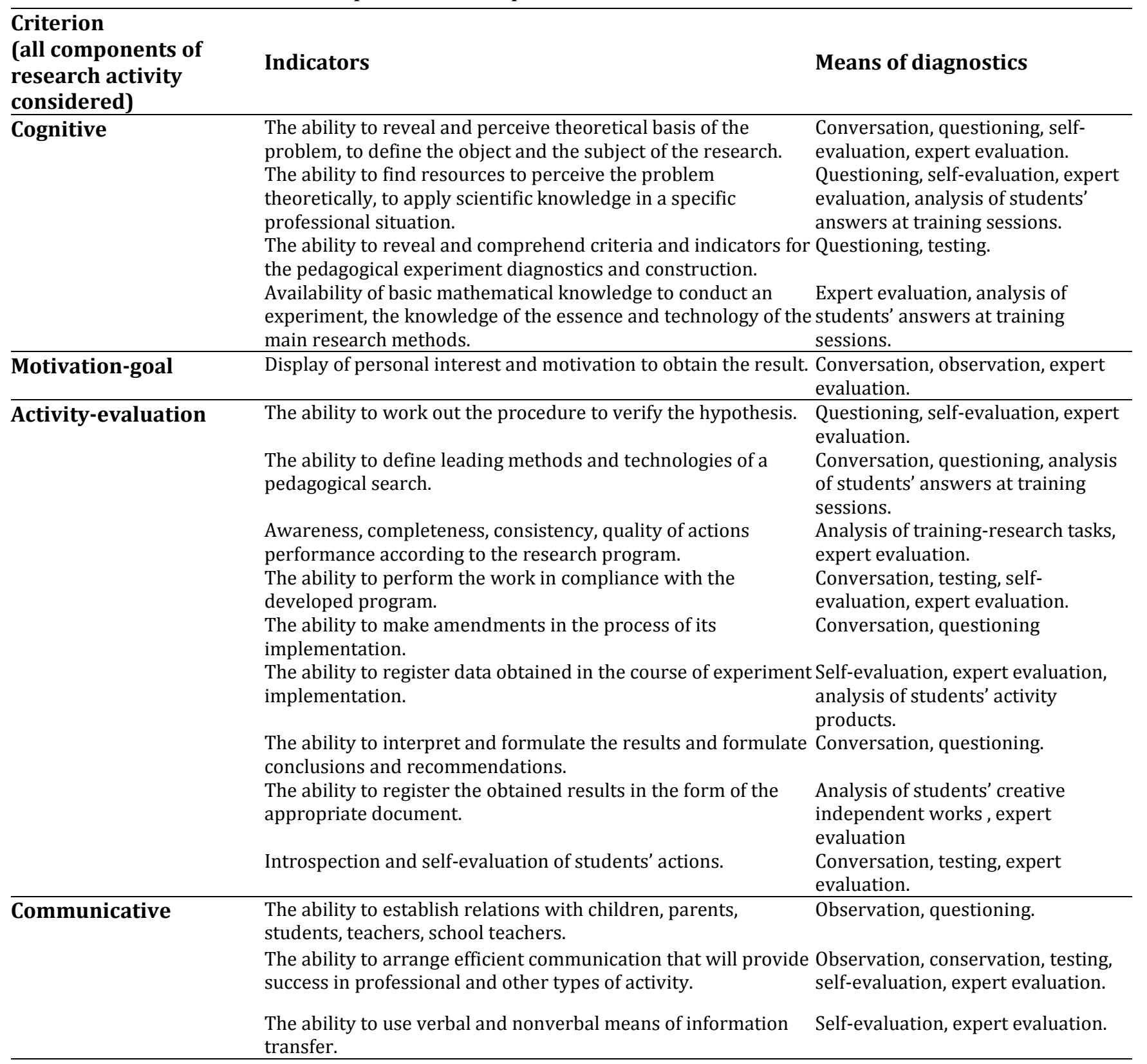

\section{RESULTS}


The experiment was applied to verify the efficiency of the developed technology to realize the model of students' motivation increase in the research activity and their involvement in the research process.

The requirements to the level of research competences development are presented in FSES of higher education in Russia. The analysis of FSES of higher education on the training directions "Physics", "Mathematics and computer sciences", and "Applied mathematics and informatics" allowed to bring about research competences which we have expressed through the following abilities:

1. To increase professional competence in the area of performed scientific research (the latest theories, interpretations, methods and technologies);

2. To reveal and formulate relevant scientific problems in the sphere of future professional activity of the mathematical profile;

3. To work out a plan and program of educational/scientific research;

4. To apply techniques and technologies from adjacent fields of knowledge in order to carry out research in the field of mathematics;

5. To interpret scientific research results and to reveal their practical importance;

6. To generalize scientific research results and to present them in the form of articles, reports, and abstracts;

7. To report scientific research results in public with the presentation of the report.

60 students of the specified training directions took part in the experiment.The assessment of the research competence development level was carried out on a threepoint scale: perfect mastery -3 , mastery- 2 , mastery is poorly expressed -1 , does not master - 0 .

The correlation of the indicator with the criteria of competence developed level: 75-100\% -optimum, 55-74\% -admissible, 25-54\% -critical, 24\% and below inadmissible level.

According to the results of the experiment, the following data shown in Table 3 was obtained.

From analyzing these tables, we were able to correlate them to the criteria of research competence development level.

The critical level of research competence development was shown by $20 \%$ of students, admissible - $36.7 \%$ of students, and optimum - $43.3 \%$ of students. Inadmissible level was not found. Therefore, the optimum and admissible levels of research competence development was shown by $90 \%$ of students that testifies to the high level of students' research work organization in the university at training sessions of mathematical disciplines and a quite high quality of research training of future experts.

Table 3.The evaluation of students' research competences development level

\begin{tabular}{llccccccc}
\hline & & \multicolumn{3}{c}{ Abilities } \\
\cline { 3 - 8 } & & $\mathbf{1}$ & $\mathbf{2}$ & $\mathbf{3}$ & $\mathbf{4}$ & $\mathbf{5}$ & $\mathbf{6}$ & $\mathbf{7}$ \\
\hline & Perfect mastery & 26.7 & 23.3 & 16.7 & 26.7 & 20.0 & 36.7 & 43.3 \\
Level of & Mastery & 63.3 & 63.3 & 63.3 & 53.3 & 80.0 & 56.7 & 36.7 \\
development & Mastery is poorly & 13.4 & 13.4 & 20.0 & - & 6.6 & - & 20.0 \\
& $\begin{array}{l}\text { expressed } \\
\text { Does not master }\end{array}$ & 10.0 & - & 6.6 & - & - & - & - \\
\hline
\end{tabular}

\section{DISCUSSIONS}


The importance to include research tasks in the content of students' educational activity in a higher education institution has been emphasized over different years by a number of scientists and teachers (Babansky, 1985; Diesterweg, 1956; Kan-Kalik, 1987; Lerner, 1981; Skatkin, 1971; Ushinsky, 1954; Shatsky, 1962).

The research (Bogoslovsky, 2000; Chugainova \& Stavrinova, 2007; Lazarev \& Stavrinova, 2007; Zagvyazinsky,1982; Zimnyaya, 2006) shows that students - future experts experience essential difficulties in solving some research tasks, and in many cases display a low level of research competence development.

The analysis of psychology and pedagogical sources showed that in pedagogical theory and practice, considerable material has accumulated on the issues of students' research competence development (Ryndina, 2011; Skornyakova, 2013). In works of many scientists, effective methods have been worked out to develop students' research competence.

In our opinion, the components of research competence are based on the idea of personal qualities of a successful person, an expert, and do not completely cover the whole process of the research. Vocational education requires such an option of research competence components so as to show the fundamental nature of research.

\section{CONCLUSION}

Society demands we have competent, creatively thinking experts, who are able to find original solutions and involve employees in research and innovative activity. The theoretical experiment confirmed the relevance of the issue, to develop students' research competence in a higher education institution, through the availability of reserves and opportunities to solve this problem in the pedagogical theory and practice.

The conducted research was aimed to develop the model of research competences development of students trained in the mathematical direction in the process of studying specific mathematical disciplines. This is in the context of an information and communication environment, in light of competence-based, personal-activity and system approaches on the basis of mathematical, information and pedagogical knowledge integration.

\section{ACKNOWLEDGMENTS}

The work has been performed according to the Russian Government's Program of Competitive Growth of Kazan Federal University.

\section{REFERENCES}

Abdrafikova, A. R., Akhmadullina, R. M., \& Singatullova, A. A. (2014). The implementation of project and research activities in working with gifted children in terms of schooluniversity network cooperation (Regional aspect). English Language Teaching, 7(12), 5459.

Babansky, Yu.K. (1985). Training methods in a modern comprehensive school. Moscow: Education.

Biktagirova, G. F., \& Valeeva, R. A. (2013). Technological approach to the reflection development of future engineers. 16th International Conference on Interactive Collaborative Learning, ICL, 2013 (pp.427-428). Kazan, Russian Federation: Kazan National Research Technological University.

Bogoslovsky V. I. (2000). Scientific maintenance of educational process in a pedagogical university: Methodological characteristics. St. Petersburg: RGPU named after A. I. Herzen.Bushmeleva, N. A., \& Razova, E.V. (2014). Competence-based approach in modern mathematical education. Relevant issues of the main and additional mathematical education. Issue 1.Concept. Retrieved from http://e-koncept.ru/teleconf/64211.html 
Chugainova, O. G., \& Stavrinova, N. N. (2007). The role of research abilities in the structure of the future teacher training for the implementation of research activities. Vestnik MGOU "Pedagogy", 2(1), 41-46.

Diesterweg, A. (1956). Selected pedagogical compositions. Moscow: Uchpedgiz.

Edwards, N. M., \& Osipova, S. I. (2011). Research competence formation for the international scientific project (monograph). International Journal of Experimental Education, 9, 30-31.

Kan-Kalik, V. A. (1987). To the teacher about pedagogical communication. Moscow: Education.

Khutorskoi, A. V. (2009). Goals and objectives of the scientific school of education. Experiment conducting in the school: The Internet, competence, heuristics. Moscow: Publishing house "Eidos", 8-16.

Khutorskoi, A. V. (2011). The innovative aspect of the competency approach in education. $T$. I.Shamova scientific legacy and its influence on the decision of actual problems of modern education. Moscow, 79-83.

Khutorskoi, A. V. (2013). Competence-based approach in training. Moscow: Publishing house "Eidos".

Komarova, Y. A. (2008). Scientific-research competence of experts: functional and content description. News of the Russian state pedagogical university named after A.I. Herzen, 11 (68), 69-77.

Latypov, N. R., \& Sabirova, D. R. (2013). Competence-based approach to aeronautical engineering education: Language aspect. 16th International Conference on Interactive Collaborative Learning, ICL, 2013, (pp.617-618). Kazan, Russian Federation: Kazan National ResearchTechnological University.

Lazarev, V. S., \& Stavrinova, N. N. (2007). Training of future teachers for research activity. Surgut: RHS SurSPI.

Lebedev E. V. (2009). Research competence development of the future managers. Author's abstract of the candidate of pedagogic sciences, Yaroslavl.

Lerner, I. Ya. (1981). Didactic bases of teaching methods. Moscow: Pedagogics.

Pidkasisty, P. I., Belyaev, V. I., Mizherikov, V. A., \& Yuzefavichus, T. A. (2010). Higher education "Pedagogics". Moscow: Publishing center "Akademiya".

Ryndina, Y.V. (2011). Research competence in the structure of key competences of a future teacher. Electronic resource: Journal of scientific publications of graduate students and doctoral candidates. 1. Retrieved fromhttp://www.jurnal.org/articles/2011/ped4.html.

Shadrikov, V. D. (2006). Personal qualities of the teacher as components of professional competence. Vestnik YGU named after P. G. Demidov, 1, 15-21.

Shatsky, S. T. (1962). Pedagogical compositions in 4 V. Moscow: Education.

Skatkin, M. H. (1971). Training process improvement. Moscow: Pedagogics.

Skornyakova, A. Yu. (2013). Formation of research competences of training in mathematics of future bachelors of pedagogical education with use of the information and communication environment. Author's abstract of the candidate of pedagogic sciences, Yaroslavl.

Ushinsky, K. D. (1954) Selected pedagogical compositions. Moscow: Uchpedgiz.

Zabelina, S. B. (2015). Methodical approaches to the organization of research activity of undergraduates of pedagogical education in the Mathematical Education direction, Scientific and methodical approaches to formation of educational programs of training in modern conditions: collection of scientific materials II of Regional interuniversity scientific and practical conference (pp.180-185). Moscow: Moscow state regional university.

Zagvyazinsky, V. I. (1982). Methodology and technique of a didactic research. Moscow: Pedagogics.

Zhirnova, G. I., \& Absalyamova, S. G. (2013). Global innovation gap and quality of education. 16th International Conference on Interactive Collaborative Learning, ICL, 2013 (pp.144145). Kazan, Russian Federation: Kazan National Research Technological University.

Zimnyaya, I. A. (2006). Key competences - a new paradigm of modern education result. Internet journal "Eidos". Retrieved from http://www.eidos.ru/journal/2006/0505.htm 